\title{
Cenplesto
}

\section{Bibliotecas escolares: tendências globais}

\author{
Kelley Cristine Gonçalves Dias Gasque \\ Doutora; Universidade de Brasília (UnB), Brasília, DF, Brasil; \\ kelleycristinegasque@ hotmail.com \\ Helen de Castro Silva Casarin \\ Doutora; Universidade Estadual Paulista (UNESP), Marília, SP, Brasil; \\ helen.casarin@gmail.com
}

\begin{abstract}
Resumo: Este artigo aborda as transformações do processo de ensinoaprendizagem e das tecnologias e o impacto dessas nas bibliotecas escolares, especificamente, na formação do acervo, na configuração do espaço e no papel dos bibliotecários. A análise da literatura mostra tendência à adoção de modelos de aprendizagem baseados na construção colaborativa do conhecimento, com ênfase na aprendizagem compreensiva e atividades de ensino em ambientes diversificados. As bibliotecas escolares podem acolher e subsidiar atividades de ensino variadas, transformando-se em locais não apenas de apropriação da informação, mas também de produção do conhecimento por meio de atividades colaborativas, conectadas e diversificadas. $\mathrm{O}$ bibliotecário precisa fortalecer o domínio de tecnologias para obtenção, gerenciamento, produção e compartilhamento de informações. O fomento à leitura continua a ser importante, mas precisa ser ampliado para diferentes suportes e formatos.
\end{abstract}

Palavras-chave: Biblioteca escolar. Tecnologia. Aprendizagem. Bibliotecário. Formação de coleções.

\section{Introdução}

A aprendizagem escolar está em transformação. Nunca se discutiu tanto sobre melhores práticas de ensino em sala de aula e os requisitos para potencializar a aprendizagem. Há razões pedagógicas e tecnológicas para tais mudanças. Nesse contexto, a biblioteca escolar também precisa estar em sintonia com essas mudanças.

Sullivan (2011), uma experiente designer de bibliotecas escolares americanas, ressalta que questões que eram importantes anos atrás não fazem mais sentido atualmente. Ela argumenta que, para projetar uma biblioteca escolar, não é mais essencial saber sobre a quantidade de livros do acervo, as medidas do espaço, o revestimento de madeira a ser usado, o número de estudantes de cada 
classe ou ainda onde a mesa de circulação deve ficar. As perguntas mais urgentes, para a autora, são: quais ferramentas e recursos os estudantes precisarão? Quais são os objetivos de aprendizagem da escola? Como os objetivos de aprendizagem podem ser integrados ao trabalho da biblioteca? Sendo assim, a biblioteca escolar precisa buscar formas de se adequar a esta realidade.

Uma inovação pode se tornar tendência ou desaparecer. Tendência pode ser compreendida como propensão, disposição, intenção, ou ainda, direção ou forma assumida por algo num dado momento, como consta no Aurélio Digital (c2016). As tendências resultam da evolução econômica, de mudanças na sociedade ou de atitudes e comportamentos. Algumas tendências emergem como oportunidades, outras como desafios ou ameaças. Aaker (2009) ressalta a importância de diferenciar tendências geradoras de crescimentos de modismos passageiros.

O presente artigo apresenta revisão de literatura do tipo narrativa. De acordo com Cordeiro et al. (2007), esse tipo de revisão apresenta temática mais aberta; e em geral, não parte de uma questão bem definida, além disso, não exige protocolo rígido para o desenvolvimento da pesquisa. Nesse caso, a busca das fontes de informação é mais flexível e menos abrangente.

Realizou-se um levantamento das tendências globais de aprendizagem, considerando os artigos escritos, em especial, em língua inglesa nos últimos cinco anos e disponíveis no portal de periódicos da Capes. Os descritores usados para pesquisa no portal da Capes foram "learning trends", "school libraries trends" e "21st century school library". A partir desse mapeamento, optou-se por organizar os conteúdos em tendências de aprendizagem, como se observa na seção intitulada "por uma nova aprendizagem". Por sua vez, o tópico sobre bibliotecas escolares foi subdividido em três, abrangendo os conteúdos mais discutidos no levantamento dos artigos, quais sejam: do impresso para o digital: aquisição de materiais e conteúdos; um novo espaço de aprendizagem e bibliotecários para novos tempos.

O objetivo dessa revisão de literatura é oferecer subsídios para reestruturação da biblioteca escolar e para a reformulação de cursos de formação de base e formação continuada dos bibliotecários atuantes em escolas; planejar novos 
produtos e serviços e consolidar o papel da biblioteca escolar no novo cenário educacional.

\section{Por uma nova aprendizagem}

Hough (2011), ao abordar as tendências para bibliotecas escolares, chama atenção para as mudanças da sociedade que impactam no preparo das novas gerações para o mercado de trabalho. O autor revela que a amplificação das tecnologias da informação e da comunicação consolida uma economia de serviços interligados, cujas características são: globalização acompanhada de demandas individualizadas; impacto das tecnologias, que provocam mudanças sociais, assim como, mudanças comportamentais nos indivíduos; modificações dos pressupostos econômicos e da «ordem social»; transformação do conhecimento em commodity valiosa, causada pela tendência de concentração da economia em bens intangíveis; mudanças nos conceitos de valor e inovação que assumem significados mais complexos e sofisticados. Este constitui o amplo cenário em que escolas e bibliotecas precisam ajudar os estudantes a se prepararem para serem bem-sucedidos no século 21.

Dessa forma, isso requer considerar a escola como mais uma fonte de aprendizagem, não a única. Sobre isso, Schlunzen Junior afirma que "[...] diante de um mundo conectado e amparado por recursos tecnológicos, a escola tende a se transformar em espaço de diálogo e discussão, uma vez que não é mais o centro nem a principal fonte de informação dos estudantes”. (JORGE, 2014).

Outro fator importante é que, nos últimos anos, a evolução nos estudos da mente trouxe consequências significativas para a educação. Um dos marcos é a ênfase na aprendizagem compreensiva e não somente na memorização. Mais do que recordar fatos, os estudantes precisam compreender o contexto em que os conhecimentos são aplicáveis. Isto é, o foco deve estar no processo do conhecimento, que por sua vez considera o conhecimento prévio e a aprendizagem ativa (BRASNFORD; BROWN; COCKING, 2007).

O grande desenvolvimento das tecnologias catalisa as escolas para um modelo de aprendizagem mais conectado e colaborativo. O relatório NMC Hori- 
zon para educação básica (JOHNSON et al., 2015) apresenta resultados de uma pesquisa colaborativa, baseada em discussões entre 56 especialistas educacionais de 22 países e seis continentes sobre as tecnologias emergentes e o potencial de impacto no processo de ensino-aprendizagem nas escolas. As principais tendências, que influenciam a adoção das tecnologias na educação, foram classificadas em três categorias: tendências de impacto a longo prazo que continuarão importantes para prazos maiores que cinco anos; tendências de impacto a médio prazo que continuarão importantes na tomada de decisões para os próximos três ou cinco anos; e tendências de impacto a curto prazo que impulsionam a adoção de tecnologia educacional agora, mas que, provavelmente, serão importantes por apenas mais um ou dois anos, tornando-se comuns ou desaparecendo nesse tempo.

Os especialistas concordam com duas tendências a longo-prazo, que devem direcionar a educação, quais sejam: (i) repensar a forma como as escolas funcionam, a fim de reforçar o envolvimento dos estudantes e obter mais inovação, bem como, (ii) a mudança para abordagens de aprendizagem mais aprofundadas, como a aprendizagem baseada em projetos. Essas tendências apresentam uma ruptura com a estrutura tradicional curricular - dividida por disciplinas e pouco interdisciplinar - em busca de um ensino globalizante.

De acordo com o relatório NMC Horizon (JOHNSON et al., 2015), em termos de impacto a médio prazo, as tendências são: aumentar a utilização de abordagens de aprendizagem colaborativas, fundamentadas na perspectiva de que a aprendizagem é uma construção social, e a mudança de estudantes como consumidores para criadores de conteúdo. Nesse caso, as ferramentas digitais disponíveis têm apoiado essas transformações na educação. Outros componentes de mudança incluem o desenvolvimento de jogos, acesso à instrução de programação, dentre outros. Conforme os estudantes se tornam produtores e editores de recursos educacionais mais ativos, questões de propriedade intelectual devem se tornar componentes chave do currículo.

Em relação à tendência a curto prazo, identificaram-se o aumento da aprendizagem híbrida, que projetado e implementado de forma eficaz, permite aos estudantes praticar e conseguir o domínio do conteúdo no próprio ritmo por 
meio de módulos de aprendizagem on-line e software adaptável; e a valorização das humanidades e das atividades artísticas que envolvem os estudantes em um contexto de aprendizagem multi e interdisciplinar, rompendo barreiras tradicionalmente existentes entre as diferentes áreas e assuntos.

Greene e Waugh (2015) também ressaltam a influência do movimento Bring Your Own Technology/Device (BYOT ou BYOD), traduzido por "Traga seu próprio dispositivo" para as escolas. A prática dos estudantes levarem as próprias ferramentas de acesso à internet e aos recursos digitais, como notebooks, celulares e tablets, por exemplo, possibilita a integração de atividades com níveis mais profundos de informação, o que, por sua vez, requer que questões como direitos de autor, filtragem, usabilidade, privacidade e segurança façam parte do currículo escolar. Além disso, tal prática implica uma atuação mais efetiva dos bibliotecários escolares.

As tecnologias permitem a aprendizagem transcender a sala de aula. Esse cenário impõe às bibliotecas escolares novas formas de atuar e ensinar. As bibliotecas escolares, de acordo com Johnson (2013), são espaços de aprendizagem social, propícios aos trabalhos de equipes, formais e informais. Nesses espaços, as novas mídias apoiam a aprendizagem conectada, fornecendo feedback e experiências de aprendizagem individualizadas. Esse modelo de aprendizagem pode ser usado em várias áreas de conhecimento, mas os principais benefícios estão em ambientes de aprendizagem fora da escola. As bibliotecas escolares que utilizam esse modelo, em geral, atuam com atividades extraclasses, por meio de clubes que trabalham com prazos.

Lippincott (2014) reforça que a ênfase no aprendizado ativo e na aprendizagem como processos sociais ensejam o desenvolvimento de habilidades de colaboração e da capacidade de comunicar de forma eficaz, em várias mídias. As bibliotecas oferecem espaços de aprendizagem para apoiar o trabalho do grupo e desenvolver competências para o compartilhamento de informações em várias mídias, além do texto escrito tradicional.

Outro desafio é o ensino contínuo voltado para o desenvolvimento de competências, para buscar e usar a informação no ambiente digital. Nesse sentido, é necessário considerar que muitos membros da equipe da escola precisam 
de liderança e apoio para lidar com o mundo em rápida mudança, com oportunidades e ameaças relacionadas à evolução da aprendizagem baseada nas TIC (HOUGH, 2011).

Shaw, Flynn e Barrett (2014) explicam que as novas tecnologias catalisam mudanças na aprendizagem, as quais podem ser resumidas em: construção de currículo orientado para investigação e reflexão; desenvolvimento da aprendizagem independente e colaborativa e aplicação do modelo de aprendizagem comum.

Considerando essas perspectivas em torno da aprendizagem, pode-se concluir que o que se busca, de maneira ampla, são experiências de aprendizagem autênticas e significativas, que propiciem aos estudantes contato com os problemas do mundo real e situações de trabalho - perspectivas essas ainda pouco frequentes nas escolas. O termo aprendizagem autêntica abrange várias abordagens e estratégias pedagógicas: resolução por problemas, projetos, ensino reflexivo, metacognição, avaliação formativa, pedagogia diferenciada, as quais são potencializadas pelas possibilidades que as novas tecnologias trazem.

\section{Do impresso para o digital: aquisição de materiais e conteúdos}

As coleções das bibliotecas escolares enfrentam desafios únicos se comparadas a outros tipos de bibliotecas. Elas precisam estar alinhadas às normativas oficiais relacionadas ao ensino; atender aos conteúdos previstos no currículo escolar de acordo com a idade e as habilidades dos estudantes; atender aos interesses recreacionais e também às demandas de atualização dos professores (SHEEHAN, $2013^{1}$ apud O'CONNELL; BALES; MITCHELL, 2015).

Nas últimas décadas, porém, esse desafio tem se somado à proliferação das mídias digitais e dos recursos eletrônicos. O material impresso abriu espaço para novas mídias como DVD's, audiobooks, streaming de vídeos, livros eletrônicos, recursos on-line. Cada vez mais os estudantes chegam às escolas com domínio do uso de recursos eletrônicos usados para diversos fins.

Ao revisar a literatura sobre o tema, O'Connell, Bales e Mitchell (2015) concluem que as bibliotecas escolares precisam se adaptar a esse contexto mar- 
cado por recursos eletrônicos, a fim de exercer uma de suas funções primordiais: a promoção da cultura de leitura na escola. Essa adaptação também é importante para “[...] facilitar a divergência e convergência em mídias necessárias para dar suporte à motivação, diferenciação, plataformas variadas, colaboração e conexões, necessárias para a nova ecologia de aprendizagem do século XXI."2 (2015, p. 15 , tradução nossa).

A tendência de acesso a conteúdos por meio de dispositivos móveis (BYOT / BYOD) é outro fator que tem impacto nas coleções e no espaço físico das bibliotecas. Taylor, Subramaniam e Waugh (2015), ao abordarem sobre tendências para as bibliotecas escolares, apontam que a "internet das coisas" ou a tecnologia responsiva, que possibilita a conexão a objetos, eletrodomésticos, entre outros, poderá ser utilizada para coletar dados em tempo real, inclusive pelos próprios estudantes e os bibliotecários irão gerenciá-los a fim de que possam ser utilizados em futuras pesquisas de outros estudantes. Assim, as coleções tradicionais serão complementadas com informações e dados para suprir as demandas dos projetos e das atividades escolares.

Muitas escolas têm repensado as regras de aquisição de conteúdos. Em vez de comprar livros para as bibliotecas, elas adquirem conteúdo digital para uso em toda a escola. A Associação Australiana de Bibliotecas e Informação (AUSTRALIAN LIBRARY AND INFORMATION ASSOCIATION, 2013) previu que, em 2020, as coleções das bibliotecas terão um equilíbrio entre documentos impressos e eletrônicos na proporção 50:50. No entanto, pesquisas não têm confirmado essa proporção tão equilibrada entre a coleção física e a eletrônica (O'CONNELL; BALES; MITCHELL, 2015, p. 15), indicando ainda predomínio do material impresso sobre o digital. Contudo, especialmente, ao se adquirir e-books e bases de dados, é necessário estudar o termo de licença. Isso porque, em geral, esses serviços não são vendidos, mas licenciados. Assim, o provedor reserva o direito de excluir o conteúdo a qualquer momento, sem aviso prévio ou obrigação de fornecer reembolso. Todavia, vale lembrar que no caso dos e-books das maiores editoras existem desafios adicionais. A maioria das grandes editoras impõem termos de licenciamento especiais para bibliotecas e 
escolas que desejam usar esses recursos (HARRIS, 2014), e o bibliotecário precisa saber lidar com esta questão.

Esses problemas, contudo, podem ser superáveis. Pequenos editores optaram por explorar novas opções digitais. Surgem, assim, opções de licenciamento para as bibliotecas escolares que incluem assinaturas anuais, licenças perpétuas e, até mesmo, aluguel a curto prazo. Além disso, as bibliotecas escolares podem trabalhar por meio de consórcio ou em modelo de rede. As estratégias de desenvolvimento de coleções devem mudar a fim de refletir o vasto leque de recursos impressos e digitais para apoiar a aprendizagem, incluindo ampla variedade de livros eletrônicos, bancos de dados e outros recursos digitais (EASLEY; YELVINGTON, 2015). Alguns autores, no entanto, indicam que, devido aos cortes de orçamento, os bibliotecários, provavelmente, se afastarão dos caros bancos de dados de assinatura, que, muitas vezes, são subutilizados para usar materiais gratuitos disponíveis na web.

Breeding (2013) também argumenta sobre a importância das bibliotecas escolares manterem colaboração com bibliotecas próximas a fim de ampliar o acervo. Porém, ao tratar da aquisição de recursos das bibliotecas escolares, ressalta-se a necessidade de assegurar recursos de acordo com o nível acadêmico. Além disso, as bibliotecas escolares ao desenvolverem as coleções, em geral, precisam respeitar o posicionamento de pais, professores e administradores da escola, no que concerne aos conteúdos e formas de abordagem usados por eles nos documentos a serem incorporados à coleção. Isso se aplica a qualquer tipo de recurso, inclusive aqueles disponíveis na Web. A filtragem de conteúdo é um elemento comum na infraestrutura de rede da escola. A natureza inclusiva de coleções da biblioteca pública - diferente dos parâmetros restritivos das escolas, pode se tornar elemento complicador na colaboração entre esses dois tipos de bibliotecas.

O uso de novos recursos muda a forma de aprender. Contar com ampla gama de recursos midiáticos possibilita aprofundar os conhecimentos. Nesse sentido, a biblioteca tradicional com estantes enfileiradas, mesas de estudos e algumas mais modernas com computadores de acesso à internet não possibilita atender todas as demandas e expectativas da sociedade de aprendizagem. Por 
isso, é necessário pensar no novo design da biblioteca escolar. Easley e Yelvington (2015) sustentam a ideia que as bibliotecas devem passar por um processo de reengenharia para apoiar a aprendizagem atual.

\section{Um novo espaço de aprendizagem}

As escolas contemporâneas enfatizam o letramento, a educação autodirecionada, a aprendizagem colaborativa, bem como, os diferentes estilos de aprendizagem; como se pode observar na literatura educacional, de maneira geral. Além disso, o fato de haver tantos dispositivos eletrônicos levanta questionamentos sobre até que ponto esses formatos substituirão os impressos nas escolas da educação básica. Essas novas concepções sobre aprendizagem contribuíram para que se pensasse em bibliotecas como espaços de aprendizagem comum ("Learning Commons"), ou que, pelo menos, incluam espaços para esta finalidade. Esse espaço deveria ter a flexibilidade necessária para ser utilizado por diferentes professores e classes; espaços para tarefas de aprendizagem em grupos baseadas em projetos e atividades multimídia; áreas para contação de histórias, apresentações ou performances; áreas para leituras ou estudo individuais e outros espaços adaptados para estudantes com necessidades especiais.

O modelo de Learning Commons refere-se a um espaço físico e virtual em que a aprendizagem é partilhada. Foi proposto em 2008, por Loertscher, Koechlin e Zwaan para substituir o laboratório de tecnologia educativa e a biblioteca escolar. Nos últimos anos, algumas escolas e distritos escolares da América do Norte experimentaram esse modelo como lugar dinâmico, onde a comunidade educativa contribui e participa dos programas e das facilidades, no qual a aprendizagem, a criatividade e a inovação são as forças motrizes (LOERTSCHER; KOECHLIN, 2012). Shaw, Flynn e Barrett (2014) salientam que Loertscher utiliza o desenvolvimento da Microsoft e do Google para mostrar a diferença entre a biblioteca escolar tradicional e o espaço comum de aprendizagem. A primeira empresa, por meio dos produtos de projetos anteriores, percebe os desejos de consumo do público, e a última projeta um grupo de ferramentas que os usuários podem adaptar às próprias necessidades. 
O relatório da NMC Horizon (JOHNSON et al., 2015) também traz recomendações sobre o espaço das bibliotecas escolares, destacando: aplicações da tecnologia educacional e os espaços de criação (makerspaces). Esse relatório descreve experiências de bibliotecas que assumiram a liderança do movimento, transformando-se em markerspaces. A adoção de impressão 3D e tecnologias de aprendizagem adaptativas são estimadas para os próximos dois ou três anos, enquanto a certificação digital ${ }^{3}$ e a tecnologia usável são esperadas nas escolas, dentro de quatro a cinco anos.

Nessa mesma perspectiva, Grigsby (2015) argumenta que o novo design da biblioteca escolar deve ser estruturado como espaço comum de aprendizagem, em que os estudantes possam trabalhar para resolver problemas. A palavrachave para a nova biblioteca é flexibilidade. Para tanto, esse espaço deveria adotar mobiliário flexível, de modo que diferentes configurações ou ambientes de aprendizagem possam ser criados para estudantes e funcionários. Há, por exemplo, empresas que oferecem prateleiras em formas flexíveis e com rodas que podem ser movidas e rearranjadas com o mínimo de esforço.

Grigsby (2015) lembra que um questionamento comum, atualmente, relaciona-se à necessidade de haver espaço físico para a biblioteca, visto que os estudantes podem acessar a informação e resolver as tarefas em casa ou na própria sala de aula. Sobre isso, a autora advoga sobre a função das bibliotecas como espaços de conversação, de interação, de encontros, bem como espaços "makers".

Espaços makers, de acordo com Canino-Fluit (2014), são espaços de criação. Por isso, em algumas bibliotecas são denominadas oficinas de criação, de fazer. Fazer (make) é uma atividade social de investigação e criação que permite aos estudantes desenvolver habilidades, disposições, responsabilidades e estratégias nos padrões do século XXI. É, portanto, uma oportunidade de abrir a biblioteca aos estudantes que querem adquirir e usar informação para criar algo.

Nesse espaço - físico ou virtual - a ideia é valorizar os vários estilos de aprendizagem mediante o "faça você mesmo" e o "fazer juntos". A intersecção entre aprendizagem formal e informal pode incluir concepção, jogos, colaboração, inquisição, experimentação, resolução de problemas e criação. Por meio do 
engajamento ativo, nesses espaços, é possível assumir o comando da própria aprendizagem, com potencial para demonstrar o comportamento empreendedor. O desenvolvimento de espaços de criação permite à biblioteca expandir e estender as interações com organizações comunitárias e de aprendizagem, empresas, famílias e mentores em todo o mundo. Essas ligações podem fornecer recursos como parcerias, patrocinadores, doadores e voluntários aos professores. Cada espaço de criação de biblioteca é único e está sempre em transição. Esses espaços têm potencial de transformar consumidores em criadores (LOERTSCHER, 2013).

Loertscher, Preddy e Derry (2013) explicam que as bibliotecas sempre incentivaram o fazer em seus espaços, embora, agora haja maior possibilidade de uso de tecnologias, ferramentas e recursos avançados. É um esforço mais centrado, dedicado e intencional que mistura criatividade e investigação. Alguns desses espaços, por exemplo, contam com impressoras 3D, estúdios de gravação, dentre outras tecnologias.

A Austrália, por exemplo, reestruturou as bibliotecas escolares para um modelo denominado iCentre (HAY, 2012). O iCentre é um espaço conduzido por uma equipe qualificada em informação, tecnologia e aprendizagem; localiza-se em um espaço central onde a funcionalidade estratégica e operacional é impulsionada por equipe e abordagem integrada; provê programas e serviços para aprendizes do século XXI; oferece serviços customizados, flexíveis, relevantes 24 horas, sete dias na semana; a pedagogia está no centro da tomada de decisão, política e prática e ainda, fornece suporte personalizado para estudantes, professores, administradores e pais.

Hough (2011) argumenta que as bibliotecas devem funcionar como iCentres, ou seja, centros para as atividades de aprendizagem digital da escola. No modelo de iCentre, proposto por Hay (2012), as bibliotecas devem ser projetadas para serem centros de informação e inovação. Hay explica que um iCentre deve ser "[...] um espaço central na escola em que informação, tecnologia, aprendizagem e necessidades de ensino são apoiadas por especialistas em informação e tecnologia qualificados." (HAY, 2010 4 apud HOUGH, 2011, p. 151 tradução nossa). 


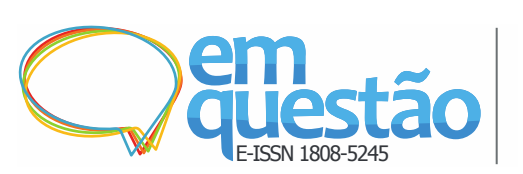

Easley e Yelvington (2015), por sua vez, consideram o modelo híbrido de biblioteca escolar, baseado no modelo de Icenter, proposto por Hay (2012) e no modelo de espaço comum de aprendizagem, proposto por Loertscher e Koechlin (2012). A autora explica que um Icenter refere-se a um espaço central na escola no qual a informação, tecnologia, aprendizagem e necessidades de ensino são apoiadas por especialistas de informação qualificados. E que o espaço comum de aprendizagem dão suporte aos quatro "Cs" de aprendizagem no século XXI, quais sejam: comunicação, criatividade, colaboração e criticidade.

Em relação ao design das bibliotecas escolares, Sullivan (2011) ressalta que deve ser direcionado para oferecer diferentes pontos de vistas, a partir de vários recursos. Isso demanda espaço mais flexível, que apoia diferentes estilos de aprendizagem; ensino múltiplos, em detrimento de um espaço que acomoda somente leituras, com mesas e cadeiras pesadas, ou ainda com estações de trabalho incorporados. Nesses ambientes, pode-se incorporar o Whiteboard ou Whiteboarding, termo usado para descrever ambiente de arquivos compartilhados. Isso requer, consequentemente, pensar na quantidade de dispositivos a serem carregados, o que demandará a incorporação de estações de carregamento. Outra recomendação da autora para as novas bibliotecas é possibilitar o contato com a natureza, por meio da integração de pátios de leitura.

Jonhson (2013) argumenta que os locais em que os jovens gostam de estar, como cafés, cinemas e ginásios, indicam que "[...] as bibliotecas deveriam ser espaços onde as crianças e jovens possam compartilhar informação e não apenas absorvê-la." (JONHSON, 2013, p. 84-85. Para o autor, as bibliotecas deveriam se tornar áreas de produção do conhecimento.

Em suma, a biblioteca escolar contemporânea deve atuar como centro de recursos de aprendizagem, com um design que demanda espaço flexível, multiuso, com mobiliário confortável e estrutura robusta de tecnologia para apoiar o acesso à rede e aos aplicativos. Isto é, uma junção do espaço comum de aprendizagem e do iCentre, dotado de espaços maker. Por isso, não faz sentido a escola contar com laboratórios de tecnologia separados desse espaço. Além disso, o bibliotecário precisa contar com uma equipe multidisciplinar para dar suporte digital ao estudante e aos professores, em um ambiente de aprendizagem colabo- 
rativa e conectada, onde o fazer, o refletir e o compartilhar possibilitam novas aprendizagens.

\section{Bibliotecários para novos tempos}

Com novos espaços e nova concepção de aprendizagem, as tecnologias demandam um novo papel dos bibliotecários, que deve ter como foco a função pedagógica e a criação do conhecimento, não se restringindo ao armazenamento, organização e recuperação de informações.

Em muitos sistemas escolares, o papel do bibliotecário torna-se o de um especialista em ferramentas digitais e em recursos que podem ser utilizados em sala de aula; assumindo também, cada vez mais, funções pedagógicas. Os bibliotecários escolares reconhecem que não são mais simplesmente curadores de recursos de impressão, mas professores, cuja sala de aula torna-se o centro da comunidade da escola. Percebem que as bibliotecas escolares continuarão a ser relevantes ao se tornarem espaços de criação e não só de recuperação da informação (GRIGSBY, 2015).

Cooper e Bray (2011) argumentam que os bibliotecários escolares de sucesso são aqueles que colaboram com os professores como parceiros plenos no processo de aprendizagem. Contudo, nem sempre as escolas, os administradores escolares e professores estão conscientes do papel educacional do bibliotecário, reconhecendo mais a função gerencial do profissional. Em consequência disso, bibliotecários não participam dos planejamentos, das ações de formação dos professores e, muitas vezes, ficam confinados às bibliotecas sem grande envolvimento no processo de ensino-aprendizagem. Esses são desafios que precisam ser superados, pois a colaboração com os professores é uma forma primária em que os bibliotecários podem demonstrar que o trabalho é parte vital da vida acadêmica e fator positivo na melhoria de desempenho do estudante.

Os bibliotecários que trabalham em consórcio, ou ainda, que adquirem recursos digitais para toda a escola, precisam compartilhar esses recursos digitais com os professores. Mais ainda, podem ajudar os professores a desenvolver novas lições e recursos para apoiar as possibilidades oferecidas pelo conteúdo 
digital, com acesso ilimitado. A biblioteca escolar moderna e os bibliotecários escolares mais eficazes fornecem apoio pedagógico para o desenvolvimento do currículo para toda a escola (HARRIS, 2014).

Marcoux (2012) reforça a contribuição dos bibliotecários, em especial, no contexto tecnológico. A autora argumenta que muitas pesquisas mostram que os estudantes são positivamente afetados pelas novas tecnologias em sala de aula, e que o envolvimento ativo é a chave desse impacto positivo. Os estudantes usam a tecnologia diária como "meio" para a aprendizagem. Nesse contexto, o letramento informacional, isto é, saber buscar e usar a informação, eficaz e eficientemente, torna-se competência a ser desenvolvida com a mediação dos bibliotecários.

Autores como Taylor, Greene e Waugh (2015) ressaltam que o objetivo principal do bibliotecário escolar continua a ser possibilitar o acesso à informação. No entanto, considerando o novo mix de tecnologia móvel, o ensino personalizado, a expansão dos espaços de aprendizagem e a intensificação do acesso e compartilhamento de conteúdos na internet pelos usuários, os autores enfatizam três aspectos fundamentais que os bibliotecários devem ensinar aos estudantes: avaliar a credibilidade das informações, respeitar os direitos autorais e proteger a privacidade. Eles sugerem que o bibliotecário escolar do futuro atue como um alquimista de aprendizagem na escola, diretamente envolvido na transformação dos espaços físicos e virtuais de aprendizagem na escola.

Easley e Yelvington (2015) ressaltam que a nova função do bibliotecário escolar se alicerça nos fundamentos da Sociedade Internacional de Tecnologia na Educação (ISTE). Ele deve atuar como líder de instrução, especialista da informação, administrador de programa, colaborador, curador digital, facilitador da e-aprendizagem, assim como, no desenvolvimento da cidadania digital. Além disso, também ressalta o trabalho com professores e administradores para selecionar recursos digitais alinhados às normas e que agregam valor ao currículo; bem como, o apoio aos estudantes e professores que usam dispositivos de computação móvel. Também destaca que as funções tradicionais como colaborar com os professores nas unidades de ensino, responsabilizar-se pela aquisição de 
conteúdo (impresso e digital) e promover o gosto pela leitura, ao longo da vida, ainda permanecem.

Hough (2011), conforme foi detalhado anteriormente nesse artigo, entende que, no contexto dos iCentres, o bibliotecário deve assumir papel de liderança pró-ativa e análogo ao do diretor de informática (CIO) nas organizações.

O novo papel do bibliotecário destaca a função pedagógica relacionada às questões como aprendizagem colaborativa e conectada, estilos de aprendizagem, integração curricular do letramento informacional, ensino híbrido, movimento maker, formação de professor, dentre outros; bem como, os recursos digitais que potencializam a aprendizagem.

O desenvolvimento de coleções, que devem incluir recursos eletrônicos variados, também requer novas habilidades e conhecimentos do bibliotecário. Segundo O'Connell, Bales e Mitchell (2015), os responsáveis pelas coleções, além de dominarem os aspectos relacionados ao paradigma bibliográfico tradicional, precisam também conhecer o funcionamento de licenças digitais, negociar contratos, conhecer dispositivos de armazenamento e gerenciamento e também se manter atualizado sobre a indústria editorial.

A literatura apresentada corrobora a proposta de Gasque (2013), ao considerar que os bibliotecários precisam desenvolver a capacidade de lidar com as questões psicopedagógicas e sociais, além das funções gerenciais e técnicas. De modo geral, a função técnica refere-se à competência necessária para o domínio das tecnologias e técnicas da profissão; a função gerencial relaciona-se à competência que possibilita a gestão das tarefas de um grupo ou organização; a função psicopedagógica refere-se ao ensino-aprendizagem e o contexto em que se insere; e por fim, a função social refere-se à competência para mediar as relações humanas.

Contudo, para que os bibliotecários possam desenvolver essas capacidades é necessário que aprendam a aprender. Precisam, portanto, ser letrados em informação para que possam continuar aprendendo ao longo da vida. O letramento informacional pode ser compreendido como "A estruturação sistêmica de um conjunto de competências que permite integrar as ações de localizar, selecionar, acessar, organizar, usar informação e gerar conhecimento..." (GASQUE; 


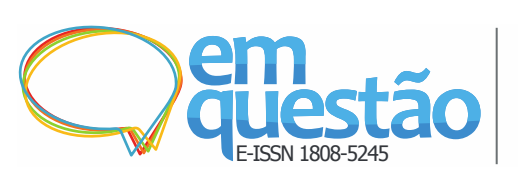

TESCAROLO, 2010, p. 41). Tal processo, desenvolvido de maneira reflexiva, permite uma formação mais orgânica, crítica, ética e independente.

\section{Conclusões}

A literatura sobre biblioteca escolar aponta que essa instituição possui importante potencial na formação dos indivíduos no contexto escolar, no sentido de prepará-los para a sociedade da aprendizagem. O uso crescente das tecnologias e o desenvolvimento de estudos sobre aprendizagem demandam mudanças no processo de ensino-aprendizagem que têm impacto direto na configuração e no papel da biblioteca no contexto escolar.

O novo cenário que se apresenta permite a identificação das principais tendências para as bibliotecas escolares para os próximos anos, considerando a aprendizagem, a coleção das bibliotecas, o espaço e o papel do bibliotecário, sintetizados no quadro a seguir.

Quadro 1: Síntese das principais tendências para as bibliotecas escolares

Aprendizagem Adoção de modelos baseados na construção colaborativa do conhecimento, com ênfase na aprendizagem ativa e compreensiva; ensino globalizante e abordagens mais aprofundadas e significativas como projetos de trabalho; ampliação e intensificação do uso das tecnologias da informação e comunicação; desenvolvimento da capacidade de buscar e usar, eficaz e eficientemente, as informações; foco na criação e compartilhamento das informações; ensino reflexivo; metacognição; avaliação formativa e pedagogia diferenciada.

Coleção

Diversificação da tipologia de documentos e de suportes e parte da coleção em formato digital; compartilhamento de recursos com outras bibliotecas e trabalho em rede; incorporação de dados e informações às vezes coletados pelos próprios usuários à coleção; incorporação de materiais através de licença de uso, juntamente com a aquisição de materiais; disponibilização de materiais para acesso por meio de dispositivos móveis; 
Transformação de espaços de armazenamento estoques de informação para espaços de interação, construção e compartilhamento de conhecimento; mobiliário flexível e dotado de equipamentos e materiais que possibilitem a realização de atividades de criação e formação formais e informais variadas.

Bibliotecário Participação ativa nas atividades educacionais da escola, em particular quanto ao uso de recursos informacionais para construção do conhecimento; competências pedagógicas e sociais; forte domínio de tecnologia; papel de liderança no uso das mesmas para acesso, uso e disseminação de informações; domínio de questões relacionadas ao direito autoral, creative commons; fomento à leitura em diferentes suportes e formatos.

Fonte: Elaborado pelos autores.

Pode-se observar que os desafios são grandes, uma vez que bibliotecários, bibliotecas escolares e muitos processos que ocorrem nesse espaço requerem mudanças para cumprir as funções educacionais, informacionais e sociais na comunidade escolar e no entorno. Nota-se um potencial para aproximação entre o bibliotecário e a comunidade em que atua, no sentido de participação ativa do bibliotecário no processo de construção do conhecimento e do trabalho em conjunto com professores e outros profissionais especialistas que precisam estar presentes no contexto escolar, em particular aqueles que dominam tecnologias, produção de mídias digitais entre outros.

Nesse contexto, embora haja grandes dificuldades e desigualdades, é preciso acompanhar essas mudanças, visto que o perfil dos estudantes de diferentes níveis tem mudado, sensivelmente, no modo como lida com a informação e como aprende. O bibliotecário, por sua vez, deve preparar-se para atuar neste cenário.

\section{Referências}

AAKER, David A. Administração estratégica de mercado. 9. ed. Porto Alegre: Bookman, 2009.

AUSTRALIAN LIBRARY AND INFORMATION ASSOCIATION. 50:50 by 2020. Kingston: ALIA, 2013. Disponível em: <http://www.alia.org.au/sites/default/files/documents/about/ALIA-5050-by- 
2020_2.pdf>. Acesso em: 20 nov. 2015.

BRASNFORD, John D.; BROWN, Ann L.; COCKING, Rodney R. (org). Como as pessoas aprendem: cérebro, mente, experiência e escola. Tradução Carlos David Szlak. São Paulo: Senac, 2007.

BREEDING, Marshall. Tech trends and challenges for K-12 school libraries.

Computers in Libraries, Medford,NJ, v. 33, n.7, p. 26-29, Sept. 2013.

CANINO-FLUIT, Ana. School library makerspaces: making it up as I go. Teacher Librarian, Lawrence, KS v. 41, n. 5, p. 21-27, jun. 2014.

CORDEIRO, Alexander Magno et al. Revisão sistemática: uma revisão narrativa. Revista do Colégio Brasileiro de Cirurgiões, Rio de Janeiro, v. 34, n. 6, p. 428-431, nov./dez. 2007. Disponível em:

<http://www.scielo.br/pdf/rcbc/v34n6/11.pdf>. Acesso em: 07 Jun. 2016.

COOPER, O. P.; BRAY, Marty. School library media specialist-teacher collaboration: characteristics, challenges, opportunities. TechTrends, Cham, v. 55, n. 4, p. 48-55, 2011.

EASLEY, Michelle; YELVINGTON, Marie. What's in a name: reimagining the school library program. Teacher Librarian, Lawrence,v. 42, n. 5, p. 21, jun. 2015.

GASQUE, Kelley Cristine Gonçalves Dias. Centro de Recursos de Aprendizagem: biblioteca escolar para o século XXI. Revista Digital de Biblioteconomia e Ciência da Informação, Campinas, v. 11, n. 1, p. 138-153, jan./abr., 2013. Disponível em:

<http://www.sbu.unicamp.br/seer/ojs/index.php/rbci/article/view/565/2057>. Acesso em: 9 jul. 2016.

GASQUE, Kelley Cristine Gonçalves Dias; TESCAROLO, Ricardo. Desafios para implementar o letramento informacional na educação básica. Educação em Revista, Belo Horizonte, v. 26, n. 1, p. 41-56, apr. 2010. Disponível em: <http://www.scielo.br/pdf/edur/v26n1/03.pdf>. Acesso em: 9 jul. 2016.

GRIGSBY, Susan. Re-imagining the 21st Century School Library: From Storage Space to Active Learning Space. TechTrends, Cham , v. 59, n. 3, p. 103106, may./june. 2015.

HARRIS, Christopher. Fact or fiction? Libraries can thrive in the Digital Age. Phi Delta Kappan, Arlington, v. 96, n. 3, p. 20-25, nov. 2014.

HAY, L. Experience the "shift": Build an iCentre. Teacher Librarian, Lawrence, v. 39, n. 5, p. 29-35, jun. 2012. 
HOUGH, Michael. Libraries as iCentres: helping schools. Australian School Library Association, Melbourne, Victoria , v. 25, n. 1, p. 5-9, 2011. Disponível em: <http://www.asla.org.au/publications/access/accesscommentaries/icentres.aspx>. Acesso em: 11 set. 2015.

JOHNSON, Doug. Power up!/ the new school library. Educational Leadership, Alexandria VA, v. 71, n. 2, p. 84-85, oct. 2013. Disponível em:

<http://www.ascd.org/publications/educationalleadership/oct13/vol71/num02/The-New-School-Library.aspx>. Acesso em: 6 jul. 2016.

JOHNSON, L. et al. NMC Horizon Report: edição educação Básica 2015. Austin, Texas: The New Media Consortium, 2015. Disponível em:

$<$ http://cdn.nmc.org/media/2015-nmc-horizon-report-k12-PT.pdf>. Acesso em: 6 jul. 2016.

JORGE, Marcos. Universidade discute inovação e acessibilidade no ensino. São Paulo: UNESP, 2014. Disponível em:

<http://www.unesp.br/portal\#!/noticia/15958/universidade-discute-inovacao-eacessibilidade-no-ensino/>. Acesso em: 6 jul. 2016.

LOERTSCHER, D. V.; PREDDY, L.; DERRY, B. Makerspaces in the School Library Learning Commons and the uTEC Maker Model. Teacher Librarian, Lawrence, v. 41, n. 2, p. 48-51, dec. 2013.

LOERTSCHER, D. V.; KOECHLIN, C. Theory and research as the foundational elements of a learning commons. Teacher Librarian, Lawrence, v. 39, n. 3, p. 48-51, fev. 2012. v. 39, n.5, p. 74, feb. 2012.

O'CONNELL, Judy; BALES, Jennie; MITCHELL, Pru. [R]Evolution in Reading cultures: 2020 vision for school libraries. The Australian Library Journal, [S.1.], v. 64, n. 3, p. 194-208, 2015. DOI:10.1080/00049670.2015.1048043

SHAW, Carolyn; FLYNN, Darren; BARRETT, Lynn. The BRIDGE LEARNING COMMONS: A whole school approach to learning for the future: first steps. The School librarian, Sydney, v. 62, n. 1 p. 3 -5, 2014.

SULLIVAN, Margaret. Divine design: how to create the 21st-century school library of your dreams. School Library Journal, New York, NY, v. 57, n. 4, p. 26-32, apr. 2011. Disponível em:

<http://www.slj.com/2011/04/sljarchives/divine-design-how-to-create-the-21stcentury-school-library-of-your-dreams/>. Acesso em: 6 jul. 2016.

TAYLOR, Natalie Greene; SUBRAMANIAM, Mega; WAUGH, Amanda. the school libraian as learning alchemist: transforming the Future of Education.

American Libraries Magazine, Chicago, fev. 2015. Disponível em: 
$<$ http://americanlibrariesmagazine.org/2015/02/26/the-school-librarian-aslearning-alchemist/>. Acesso em: 9 set. 2015.

TENDÊNCIA. In: DICIONÁRIO do Aurélio Online. c2016. Disponível em: $<$ http://dicionariodoaurelio.com>. Acesso em: 12 set. 2015.

\section{School libraries: global trends}

Abstract: This article discusses the technology and teaching/learning process transformation and the impact of these changes at the school libraries, specifically in terms of collection development, space design and the role of librarians. The literature analysis shows a tendency to adopt learning models based on collaborative construction of knowledge, with an emphasis on understanding learning and teaching activities in several environments. The school libraries can accept and subsidize the varied teaching activities, transforming itself not only in a place of information appropriation, but also in a place where knowledge is produced through connected and diversified collaborative activities. The librarian needs to strengthen their domination of technology in order to obtain, manage, produce and share information. The reading incentive continues to be important but it needs to be expanded to different media and formats.

Key-words: School library. Technology. Learning. Librarian. Collection development.

Recebido: 07/12/2015

Aceito: $21 / 06 / 2016$

${ }^{1}$ SHEEHAN, K. (2013). The ebook revolution: A primer for librarians on the front lines. Santa Barbara, CA: Libraries Unlimited, 2013.

2 "[...] facilitate the divergence and convergence in media needed to support motivation, differentiation, a variety of platforms, collaboration and connections necessary for the new learning ecology of the twenty-first century." (O'CONNELL; BALES; MITCHELL, 2015, p. 15).

${ }^{3}$ Certificação digital é uma forma de conceder certificação para a aprendizagem formal e informal na forma de microcrédito, que avalia habilidades aprendidas com base em resultados (JOHNSON, 2015).

${ }^{4}$ HAY, L. Experience the "shift": Build an iCentre. Teacher Librarian, Lawrence, KS 66044, v. 39 , n. 5 , p. 29-35, jun. 2012 